\title{
I. On oscillatory discharges
}

\section{A. Battelli \& L. Magri}

To cite this article: A. Battelli \& L. Magri (1903) I. On oscillatory discharges, Philosophical Magazine Series 6, 5:25, 1-34, DOI: 10.1080/14786440309462897

To link to this article: http://dx.doi.org/10.1080/14786440309462897

\section{Published online: 15 Apr 2009.}



\footnotetext{
Џll Article views: 3
}

Q View related articles ¿




T H E

LONDON, EDINBURGH, AND DUBLIN

PHILOSOPHICAL MAGAZINE

AND

JOURNAL OF SCIENCE.

[SIXTH SERIES.]

JALUARY 1903.

I. On Oscillatory Discharges.

By A. Battelli and L. MagRi*.

PART I.

General Description of Method.

1. THOUGH experiments have been made for some time

1 in order to test Thomson's $\uparrow$ theory of condenser discharges, no systematic and simultaneous study has, so far, been effected of the influences capable of modifying in the case of those discharges the period of oscillation, as the experimental disposition hitherto employed failed to prove adequate for researches extending over any considerable ranges, and did not allow of taking account of-if not all-even the principal elements.

Nor has the importance of the spark ever been carefully considered ; notwithstanding Cardani's and Heydweiller's researches, no exact value of its resistance has been obtained, according to the most considerable mutability of the spark from one case to another, and the variability of its resistance, from the moment of its beginning to the moment of its disappearing. Moreover, in the case of oscillating discharges the current is not uniformly distributed over the whole section of the conductor.

This complication-modifying, as was first shown by Maxwell, and afterwards more fully by Lord Rayleigh,

* Communicated by the Authors.

+ Phil. Mag. [4] v. p. 393 (1853).

Phil. Mag. S. 6. Vol. 5. No. 25. Jan. 1903. 
Stefan and Barton, the value of the resistance and the selfinduction-has been taken into account only in the case of discharges along rectilinear wires, the true resistance and the true self-induction for rapidly oscillating currents having been calculated in this special case only.

Finally, to treat this argument in a complete manner there would be required the knowledge of the energy spent in the different parts of the circuit, including the spark; and, as a matter of fact, a study of this distribution has formed the object of important researches, such as those of Riess, Paalzow, Villari, and more recently of Heydweiller and of Cardani; but in all the experiments above mentioned, though the relation between the measured quantities and the capacity, self-induction, and resistance of the circuit is allowed for, yet it is not ascertained how the distribution of energy may be influenced by the period of discharge. In the case of oscillating discharges, in fact, measurements have been made either for a single value of the period of oscillation only, or those made for different periods, by different experimenters, are difficult to compare with each other. A general and systematic study of such elements as may have a bearing on the oscillatory discharge phenomenon is therefore wanting. This we intended to undertake.

2. In this paper we give an account of the first part of our researches, the results arrived at being already worthy of notice. For these experiments we connected in the same apparatus :

(1) A device for measuring the period of oscillation;

(2) Condensers free from the defect of delay of polarization, and circuits with exactly known coefficients of self-induction;

(3) Special calorimeters to determine the amount of heat evolved by the discharges, either in the spark or in the metallic circuit traversed by them;

(4) An electrometer enabling the potential of discharge to be exactly measured;

(5) A device for determining the residual discharge ;

i. e., such apparatus as might enable us to know the period of oscillation, energy disposable at the beginning of the discharge, quantity of electricity effectively discharged, and the energy dissipated in the form of heat in the different parts of the circuit.

\section{Measurement of Peiriod of Oscillation.}

A. Anterior Researches.

3. Since Feddersen's beautiful experiments, calling the attention of physicists to the phenomenon of condenser 
discharges, numerous researches have been performed, either to show experimentally the existence of electrie oscillations, or to test the well-known theoretical formula

$$
\mathrm{T}=\frac{2 \pi}{\sqrt{\frac{1}{\mathrm{LC}}-\frac{\mathrm{R}^{2}}{4 \mathrm{~L}^{2}}}}, \quad \cdot \cdot \cdot \cdot \cdot \cdot
$$

established by W. Thomson [Lord Kelvin] for the period of oscillation.

These experiments-which we think useful to record briefly - may be divided into two groups, according as they were made in order to ascertain the value of $\mathrm{T}$ by Feddersen's method, or with a view to determine the curve representing the time variations of the intensity of the charge or discharge current of a condenser.

4. Experiments performed with Spark-Photographs.H. Feddersen * was the first to measure the period of the oscillatory discharge of a condenser, by photographing the spark after its reflexion by a rotating mirror; but as he did not make any absolute measurements of the capacity and self-induction, he only obtained qualitative laws, which we do not think worth while recording here.

Feddersen's experiments were then repeated by Lorenz $\dagger$, who stated that the values calculated for the duration of oscillation of the discharge, though corresponding to those observed as regards order of magnitude, were always somewhit higher, probably on account of the too small value ascribed to the dielectrical constant of the glass forming the insulating medium of the condensers used.

In order to eliminate this cause of uncertainty, Trowbridge and Sabine $\ddagger$ tested the discharge of an air-condenser by photographing the spark by means of Feddersen's method. They found the formula

$$
\mathrm{T}=2 \pi \sqrt{\mathrm{LC}},
$$

to which (1) is reduced for small values of $R$-as was the case in their experiments-to be fairly well verified, provided the value of $L$ as calculated by Rayleigh's formula for rapidly alternating currents be adopted. The values of $\mathrm{T}$ obtained are of the order of 0.0000031 sec., in most satisfactory agreement with theoretical values.

* Pogg. Ann. ciii. p. 69 (1858) ; criii. p. 497 (1859); cxiii. p. 437 (1.861) ; cxvi. p. $132(1862)$.

+ Wied. Amn. vii. p. 161 (1879).

† Phil. Mag, xxx. p. 323 (1890). 
Without discussing at length Boys's * experiments (their main object being a didactical one), where the spark was photographed by means of a rapidly turning objective, we rather wish to point out those undertaken by Miesler $\dagger$, with a view to test Thomson's formula. He photographed the spark due to the discharge of some leyden-jars by means of a lens and of a plane mirror set rotating by clockwork, using a circuit formed by several brass spirals : the periods found ranged from $0 \cdot 000016$ to $0 \cdot 0000052$ sec., which agrees well with theoretical values.

But specially remarkable on account of the favourable experimental conditions and the accuracy of the measurements are the researches carried on by Lodge and Glazebrook $\ddagger$, who, using an air-condenser and an induction-coil of great self-induction but small resistance, photographed the spark of discharge on a rotating plate, the velocity being capable of being maintained constant and being measured with great accuracy. Though Lodge and Glazebrook's measurements are relative to very slow oscillations only (from $\frac{1}{880}$ to $\frac{1}{1600}$ sec.), yet their results are of special importance, as the single determinations exceed in accuracy those of all previous experimenters.

In order only to show the rapidity of oscillations so far reached in those spark photographs, we will mention that much shorter periods (of the order $\frac{1}{5,000,000}$ sec.) have been investigated by Decombe $\$$, who photographed the spark of a Hertz resonator by combining a lens and a rotating mirror; and Trowbridge and Duane $\|$, in a paper where the velocity of transmission of electrical oscillations in metallic wires was tested, photographed, by the usual method of the rotating mirror, sparks of a period of about $2 \times 10^{-7}$ sec.

5. Experiments performed by the method of charge and discharge curves. - The values of the period of oscillation may conveniently be derived from the form of the curves representing the behaviour of the charge or discharge of a condenser, both of them taking place through a circuit containing a resistance and a self-induction.

Among the most accurate researches made with this method there are to be quoted Hiecke's I mensurements, whose results agree perfectly with theoretical deductions.

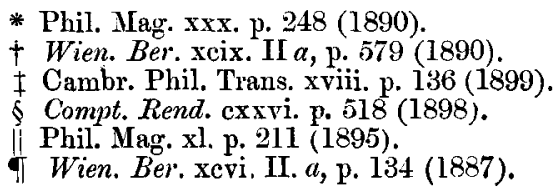


More recent experiments are those of Robb*, who kept the condenser in communication with the source of electricity for intervals gradually increasing from very small values, determined by the duration of the contact established by two steel spheres striking against one another; but the uncertainty attending this method of evaluating the duration of the time of charge imparts to those experiments a merely qualitative character.

Similarly $W u l f t$, in an investigation on the dissipation of energy in dielectrics, determined by means of an interrupter moved by a falling weight the curve of residual discharge; and whereas for condensers not subject to the phenomenon of charge-penetration he obtained values agreeing well with those calculated from the formula $\mathrm{T}=2 \pi \sqrt{\mathrm{LC}}$, he found notable departures in the case of two paraffin-paper condensers.

Tallqvist's $\ddagger$ experiments afford more adequate arrangements for quantitative verifications. By means of a pendulum interrupter, he obtained a satisfactory verification of the formula expressing the charge of a condenser as a function of time, for periods of about five-thousandths of a second; and so do Seiler's similar researches, equally carried on with a pendulum interrupter allowing of still more exact measurements of the time of charge.

Seiler first found the formula $\mathrm{T}=2 \pi \sqrt{\mathrm{LO}}$ to be verified for periods ranging from 0.0012 to 0.0045 sec., $\mathrm{L}$ being maintained constant and $\mathrm{C}$ taking variable values; but he failed to state a satisfactory agreement between the experimental values of the logarithmical decrement of oscillations and those derived from theory.

Similar investigations, based upon Helmholtz and Schiller's§ classical method, have recently been made-for periods between 0.0000246 and 0.0000586 sec.-by Webster lí, using an air-condenser and two spirals wound in a suitable way, so as to cause their capacity to be negligible. The interruption of contacts was effected, instead of by the pendulum, by means of a weight falling down from different heights (of about $75 \mathrm{~cm}$.) ; by starting successively two levers, this device enabled-according to Webster's statements-measurements of time intervals as small as $0.0000005857 \mathrm{sec}$. to be made.




6. In the table given below the values of periods, as so far observed, are recorded :-

Periods of oscillation of discharges.

a. Determinations by spark photographs.



b. Determinations by curves of charge and discharge currents.

Tallqrist (1897) ................. from 2.18 to $9.65 \times 10-3 \mathrm{sec}$.

Seiler $(1897) \ldots \ldots \ldots \ldots \ldots \ldots \ldots \ldots \ldots$ from 1.4 to $4.47 \times 10-3$,"

Webster $(1898) \ldots \ldots \ldots \ldots \ldots \ldots \ldots$ from 2.4 to $5.8 \times 10^{-5}$,"

It should, however, be borne in mind that only Trowbridge and Sabine's, Miesler's, and Lodge and Glazebrook's investigations are really oscillation measurements by method $(a)$. Now the investigations of Trowbridge and Sabine, as well as of Lodge and Glazebrook, though important on account of their being made with great accuracy, are each of them relative to one particular ease only, and do not, therefore, afford a complete verification of this theory. As regards Miesler's researches, made in more variable conditions, it will be shown below that the values derived from them cannot be said to be reliable, on account of the uncertainties attending the measurements of time and of spark-photographs. The investigations made by method (b) are, on the other hand, fairly satisfactory; but the periods reached there are not very short ones.

It was therefore desirable to undertake new and more extensive researches on so important a question.

Of the two methods used in those researches that of the curves of condenser charges and discharges - no sparks being comprised in the circuit-will most approach the theoretical conditions which served to establish the above formula; but in addition to the imperfections proper to this method, it does not refer to the cases of greatest practical importance, a spark being always produced in those cases.

As regards such imperfections as attend this method the principal one is that relative to the measurements of the time passing between the breaks of contacts, effected either by a pendulum or a falling weight. In fact, though theoretical considerations may lead us to regard extremely small fractions of a second as capable of being measured, those ten-millionths of a second are hardly to be relied upon, as Webster assumes 
(see above), except in the case of the weight determining the openings of contacts having a very great velocity $(15 \mathrm{~mm}$./sec. at the least), and special devices being employed enabling the action of the opening spark to be rendered either negligible or, at the least, constant.

In addition to what has been said it should be borne in mind that those indirect methods cannot be used in the case of very short periods, they being, at the most, capable of ascertaining with security periods not inferior to some tenmillionths of a second.

The method of spark-photographs, on the other hand, in addition to its allowing very short periods to be measured, is capable of affording also an idea of the importance of such modifications as the spark produces in the movement of electricity.

Among the forms of apparatus used with this method (e.g. the classical rotating mirror arrangement, Boys' rotating objective, Lodge and Glazebrook's rotating photographical films), the two latter ones do not afford a means of reaching very high angular velocities, in addition to their being inadequate for periods of some millionths of a second.

The turning-mirror arrangement is, without any doubt, the one enabling even very small periods to be measured, provided all those special precantions enumerated below be taken in effecting them.

\section{B. Method and Apparatus used in our Experimental Measurement of the Period.}

7. On account of the reasons above quoted we adopted the rotating-mirror method,

In this method the necessary condition for exact measurements is that the distance between the different luminous intervals composing the image of the discharge may be of sufficient magnitude with respect to the width of those intervals. Within certain limits this may be obtained by diminishing the magnitude of the image of the spark, and employing high velocities of this image on the film; this velocity being given by

$$
v=4 \pi r a,
$$

$r$ being the distance of the film from the mirror, and $a$ the number of turns effected in a second by the latter.

For practical use it proves more convenient, as a rule, to take $r$ as great as possible and to chose moderate values of $a$ (from 60 to 200 turns per second). But in order not to complicate the apparatus by adding rotating arms (similar to 
those used by Feddersen and by Trowbridge and Sabine to enable the spark to be produced at the very moment of the mirror being in convenient position for reflecting its image on the photographie film), we preferred adopting a form of apparatus capable of imparting to the image an extremely great angular velocity and of making $r$ very small. This arrangement, moreover, allowed of fairly luminous images of the spark being obtained, photographic films of moderate size being employed.

During the first part of our investigations we employed a Froment clockwork, whose last axis conld effect about 450 turns per second, but not even this velocity was sufficient in all our researches. Moreover, as is always the case with those instruments where only the friction and resistance of the medium is made use of to regulate the velocity, we found it impossible to maintain the movement constant.

This defect, inevitable in the case of rotating instruments driven by clockwork, may arouse some doubt as to the accuracy of the results obtained by Miesler.

For the same reason we rejected our first sets of observations, adopting, for the definite investigations, to produce the rotation of the mirror, a special turbine whose action we found to be perfectly regular.

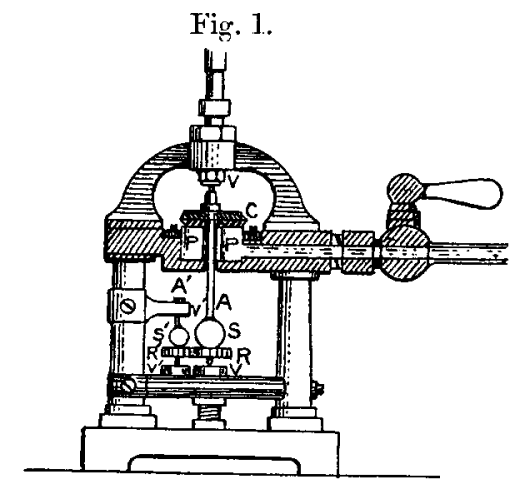

8. This turbine, constructed by the mechanician of our Institute, Mr. Giuseppe Pierucci, as represented by fig. 1 , is in its essential parts similar to that of Foucault.

The steam enters the chamber PP, and leaving it by two openings strikes against the wreath of vanes $\mathrm{C}$, fixed on the spindle $A$, together with the steel mirror $S$ and the toothed wheel R.

This latter gears into another perfectly similar wheel R', 
secured to the spindle $A^{\prime}$, where in the ordinary manner the mirror $S^{\prime}$ is fixed. The spindles are kept in position by the screws $\mathrm{VV}, \mathrm{V}^{\prime} \mathrm{V}^{\prime}$. These screws are pierced through their whole length, and they carry sapphire pillows, also pierced in order to allow of an abundant oiling, which has to be made all the time the turbine is working.

At the beginning we availed ourselves of a much overheated jet of aqueous vapour to start the apparatus, but later on we found it more convenient and suitable to make use of a jet of air compressed to 6 atm., taken from a large reservoir.

The regularity of speed of the turbine depends very much on the oiling of the spindles, which should be continuous but not excessive. The rotation of the axis becomes in fact very irregular by lack of oil, the friction being then too great, as well as by an excess of it, as in this case some oil will enter between the moving disk and the distribution box.

It is, moreover, absolutely necessary that the air injected into the turbine should not carry any oil drops on to the pump, nor dust particles of any considerable size, as the turning and the fixed parts are distant from one another only $\frac{2}{10}$ of a millimetre. To ensure this the air was admitted through a large recipient fitted with a long filter formed by several sheets of straight metallic nets.

To ascertain the velocity of rotation a small and light aluminium disk, to whose edge a short hair was attached, was fixed on the axis $A$ of the turbine. Next to this disk a rotating brass cylinder covered with smoked paper was disposed, the hair making a mark on the paper at each turn of the axis of the turbine.

The time interval corresponding to the interval hetween two marks made by the hair, and hence the number of turns effected per second by the rotating axis, was deduced in the usual manner from a comparison with the oscillation curve of an electromagnetic tuning-fork (whose period of oscillation was accurately known), recorded on the same cylinder.

A conveniently regulated clockwork was fitted with a contrivance enabling the cylinder to effect one turn only, with suitable velocity, so that the cylinder, after a small fraction of a turn (say about $\frac{1}{6}$ ), reached a fairly constant speed.

Fig. 2 (p. 10) represents a general view of the turbine, the rotating cylinder, and the tuning-fork.

Two solid iron rods, fastened on the turbine columns, carried a small frame with the photographic plate, whose dimensions were $3 \times 12 \mathrm{~cm}$. 
Fig. 2.



9. The spark to be photographed was produced in A (fig. 3) within a large wooden box, intercepting any irradiation of light by the spark.

Fig. 3.



This box, $\mathrm{C}$, had a hole $\mathrm{O}$ capable of being opened and closed by means of an ordinary pneumatic shutter, as used in photography.

A card-paper tube reaching as far as the objective $L$ (an astigmatic Zeiss objective) projected from 0 . The image formed by $\mathrm{L}$ was rellected by the rotating mirror $\mathrm{S}$ on to the photographic plate $\mathrm{F}$, if the mirror was in the proper position. 
A suitable screen prevented the light emitted by the opening sparks of the electromagnetic tuning-fork falling on the photographic plate (so as to avoid any ghosts prejudicial to the clearness of images).

10. Experiments were carried on in the following way :The pressure of air in the reservoir having reached 5 to 6 atmospheres, the photographic plate was placed in position; then, after starting the electromagnetic tuning-fork, the compressed air was led into the turbine, the rate of its entering the turbine being regulated by means of a convenient screw-cock, enabling the velocity to be auginented slowly and regularly until the suitable value was reached; comparison of the note produced by the movement of the axis with that given by the electromagnetic tuning-fork, afforded a means of ascertaining approximately whether this velocity had been reached.

As a rule, this was so considerable that the proper sound of the turbine had already exceeded the limit of perceptibility, and the sound of the axis was alone to be heard. The constancy of this latter sound, and hence the uniformity of speed, could be stated with certainty from a comparison with the sound produced by the electromagnetic tuning-fork maintained in vibration during the experiments. Those two sounds, in the case of most of our experiments, were nearly in unison.

After having, in the above manner, ascertained the uniformity of speed of the turbine, the discharge between the spheres of the spark-gap was produced, and immediately on detecting on the photographic plate the reflected image of the mirror, the shutter of the objective was closed, and the rotating cylinder was started, the axis of the turbine and the point of the tuning-fork tracing the respective curves on it. Accordingly we had but to develop and to fix the film by the usual processes.

As a rule 6 or 7 photographs per period of oscillation were taken for each explosive distance.

11. The experiments being finished the velocity of the image was easily deduced from that of the mirror and the distance between this latter and the plate; a measure of the speed of the mirror was next obtained directly from the formula

$$
\mathrm{N}=\frac{517 \cdot 2 \cdot n^{\prime}}{n},
$$

$n$ being the number of vibrations included in a certain part of the curve, and $n$ the number of lines traced on the corresponding part of the curve by the hair connected to the axis of the turbine, $517 \cdot 2$ being the number of complete oscillations made by the tuning-fork in a second at $25^{\circ}$. 
In this first part of our experiments (where we always made use only of one axis of the turbine) the velocity of the image on the photographic plate was

$$
\mathrm{V}=4 \pi d \mathrm{~N}
$$

$d$ being the distance between the mirror and the plate, this distance being in our case equal to $19.4 \mathrm{~cm}$.

In order to determine the distances between the images of the different partial sparks, special care and a certain amount of practice was found to be necessary. With our preliminary experiments this determination was effected by making use of a Froment comparator divided in half-millimetres, the vernier giving one-hundredth of a millimetre. On the moving part of this comparator, carrying the vernier, an eyepiece of small magnifying-power with a cross hair was fixed. Measurements on the plate were made four times, twice in either direction, the mean value being adopted.

We never found any noticeable differences in the value of the distances comprised between the single sparks corresponding to complete periods.

But as these measurements will often be attended by too great uncertainty towards the end of the discharge owing to the feeble luminosity, we took care to reject those last sparks in our determinations.

In all cases, however, we made measurements for one and the same discharge as well for such sparks as exhibited a maximum luminosity at the upper electrode, as for those that showed it at the inferior electrode.

The reading of those distances ( $\mathrm{N} \mathrm{A}, \mathrm{N} \mathrm{B}$, fig. 4), as determined directly on the plates, was then reduced to the arc of the circle. The arc $\alpha=\mathrm{A}^{\prime} \mathrm{B}^{\prime}$ will afford the value of $\mathrm{T}$ by means of the formula

$$
\mathrm{T}=\frac{n}{4 \pi .517 \cdot 2 \cdot n^{\prime} \cdot p} \alpha,
$$

this formula being very suitable for numerical calculations.

12. We give in the annexed tables some examples relating to the measurements of period of oscillation. $\mathrm{D}$ and $\mathrm{D}^{\prime}$ are the distances $\mathrm{NB}$ and $\mathrm{NA}$ respec-


tively of fig. $4, n$ and $r^{\prime}$ the numbers of vibrations of the tuning-fork and of the turns of the turbine connted on corresponding parts of the respective graphs, $p$ is the number of periods comprised on the measured part of the plate. 
Experiments with the large spiral wound on marble. Selfinduction of the spiral $4546000 \mathrm{cms}$. Capacity of condenser $\mathrm{C}=14175 \mathrm{cms}$. $\mathbf{T}=\frac{2 \pi}{v} \sqrt{\mathrm{LC}}=0.00005317 . \quad$ Explosive distance $2 \mathrm{~mm}$.

\begin{tabular}{|c|c|c|c|c|c|c|}
\hline $\begin{array}{l}\text { Number } \\
\text { of order } \\
\text { of Plate. }\end{array}$ & $n$. & $n^{\prime}$. & D. & $\mathbf{D}^{\prime}$ & $p$ & $\mathrm{~T}$. \\
\hline 14\{ & $\begin{array}{c}148 \\
\ldots \ldots\end{array}$ & $\begin{array}{l}24 \\
\ldots \ldots .\end{array}$ & $\begin{array}{l}5 \cdot 0495 \\
4 \cdot 4705\end{array}$ & $\begin{array}{l}0.5205 \\
0.0015\end{array}$ & $\begin{array}{l}4 \\
4\end{array}$ & $\begin{array}{l}0.00005404 \\
0.00005374\end{array}$ \\
\hline 15 & $\begin{array}{l}138 \\
\ldots \ldots .\end{array}$ & $\begin{array}{l}21 \cdot 8 \\
\ldots \ldots .\end{array}$ & $\begin{array}{l}2 \cdot 818 \\
3 \cdot 423\end{array}$ & $\begin{array}{l}4 \cdot 748 \\
5 \cdot 280\end{array}$ & $\begin{array}{l}7 \\
8\end{array}$ & $\begin{array}{l}000005339 \\
000005363\end{array}$ \\
\hline 16 & $\begin{array}{c}122 \\
\ldots \ldots .\end{array}$ & $\begin{array}{c}18 \cdot 9 \\
\ldots \ldots .\end{array}$ & $\begin{array}{l}5 \cdot 326 \\
4 \cdot 706\end{array}$ & $\begin{array}{l}2 \cdot 031 \\
1 \cdot 431\end{array}$ & $\begin{array}{l}\mathbf{3} \\
\mathbf{3}\end{array}$ & $\begin{array}{l}0 \cdot 00005417 \\
0 \cdot 00005434\end{array}$ \\
\hline 17 & $\begin{array}{l}151 \\
\cdots \ldots .\end{array}$ & $\begin{array}{l}30 \\
\cdots \cdots\end{array}$ & $\begin{array}{l}2 \cdot 1675 \\
1 \cdot 4875\end{array}$ & $\begin{array}{l}4 \cdot 7525 \\
5 \cdot 3945\end{array}$ & $\begin{array}{l}5 \\
5\end{array}$ & $\begin{array}{l}0.00005444 \\
0.00005386\end{array}$ \\
\hline 18 & $\begin{array}{c}156 \\
\ldots \ldots\end{array}$ & $\begin{array}{l}35 \\
\ldots \ldots .\end{array}$ & $\begin{array}{l}5 \cdot 433 \\
4 \cdot 605\end{array}$ & $\begin{array}{l}0.712 \\
0.021\end{array}$ & $\begin{array}{l}3 \\
3\end{array}$ & $\begin{array}{l}0.00005403 \\
0.00005303\end{array}$ \\
\hline 19\{ & $\begin{array}{c}133 \\
\cdots \cdots .\end{array}$ & $\begin{array}{c}23 \cdot 9 \\
\cdots \cdots\end{array}$ & $\begin{array}{l}2.54 \\
1.97\end{array}$ & $\begin{array}{l}4 \cdot 84 \\
4 \cdot 096\end{array}$ & $\begin{array}{l}6 \\
5\end{array}$ & $\begin{array}{l}0.00005347 \\
0.00005296\end{array}$ \\
\hline
\end{tabular}

Theoretical value $0 \cdot 00005317$. Mean value $0 \cdot 00005376$.

Experiments with the small spiral wound on ebonite. Total self-induction of circuit $57797 \mathrm{cms}$. Capacity of condenser $\mathrm{C}=3568$ ums.

$\mathrm{T}=\frac{2 \pi}{v} \sqrt{\mathrm{LC}}=0.00003008$. Explosive distance $2 \mathrm{~mm}$.

\begin{tabular}{|c|c|c|c|c|c|c|c|}
\hline $\begin{array}{l}\text { Number } \\
\text { of order } \\
\text { of Plate. }\end{array}$ & $n$. & $n^{\prime}$. & D. & $\mathbf{D}^{\prime}$ & $p$. & T. & Remarks. \\
\hline\{ & 122 & 122 & $\begin{array}{l}2 \cdot 656 \\
2 \cdot 827\end{array}$ & $\begin{array}{l}5 \cdot 005 \\
5 \cdot 226\end{array}$ & $\begin{array}{l}6 \\
6\end{array}$ & $\begin{array}{l}0.000002986 \\
0000003037\end{array}$ & \\
\hline 2\{ & 147 & $149 \cdot 2$ & $\mid \begin{array}{l}3 \cdot 365 \\
3 * 342\end{array}$ & $\begin{array}{l}1.682 \\
0.345\end{array}$ & $\begin{array}{r}13 \\
9\end{array}$ & $\begin{array}{l}0.000003011 \\
0.000003173(?)\end{array}$ & \\
\hline 3 & ...... & $\cdots \cdots$ & ...... & $\cdots \cdots$ & ....... & ......... & Not distinct. \\
\hline\{ & 1.44 & $144: 3$ & $1 \cdot 2975$ & \begin{tabular}{|l|l|}
$5 \cdot 2485$ \\
$4 \cdot 3095$
\end{tabular} & $\begin{array}{r}10 \\
8\end{array}$ & $\begin{array}{l}0.000003032 \\
0.000003053\end{array}$ & \\
\hline 5 & 126 & $129 \cdot 8$ & $\begin{array}{l}4 \cdot 683 \\
4 \cdot 934 \\
0 \cdot 265 \\
0 \cdot 056\end{array}$ & $\begin{array}{l}1 \cdot 077 \\
1 \cdot 300 \\
3 \cdot 721 \\
3 \cdot 462\end{array}$ & $\begin{array}{r}9 \\
9 \\
10 \\
9\end{array}$ & $\begin{array}{l}0.000003011 \\
0 \cdot 000003022 \\
0.000003034 \\
0 \cdot 000002981\end{array}$ & $\begin{array}{l}\text { Two sparks following } \\
\text { one another in short } \\
\text { intervals on the plate } \\
\text { were measured. }\end{array}$ \\
\hline 6 & 129 & 131 & $\begin{array}{l}3 \cdot 517 \\
3 \cdot 685\end{array}$ & $\begin{array}{l}5 \cdot 062 \\
5 \cdot 316\end{array}$ & $\begin{array}{l}4 \\
4\end{array}$ & $\begin{array}{l}0.000002904(?) \\
0.000003039\end{array}$ & \\
\hline\{ & 144 & $147 \cdot 3$ & $\begin{array}{l}0 \cdot 611 \\
0 \cdot 791 \\
2 \cdot 281 \\
2 \cdot 10\end{array}$ & $\begin{array}{l}4 \cdot 976 \\
4 \cdot 718 \\
4 \cdot 300 \\
4 \cdot 928\end{array}$ & $\begin{array}{r}14 \\
14 \\
5 \\
7\end{array}$ & $\begin{array}{l}0 \cdot 000003036 \\
0.000003001 \\
0.000003042 \\
0 \cdot 000003021\end{array}$ & \\
\hline
\end{tabular}

Theoretical value $0 \cdot 000003008$. Mean value $0 \cdot 000003024$. 
Experiments with circle-shaped circuit of copper wire. Total self-induction of circuit for $\mathrm{T}=0.00000120,9242 \mathrm{~cm}$. Capacity of condenser $\mathrm{C}=3568 \mathrm{cms}$. $\mathrm{T}=\frac{2 \pi}{v} \sqrt{\mathrm{LC}}=0 \cdot 000001201$. Explosive distance $5 \mathrm{~mm}$.

\begin{tabular}{|c|c|c|c|c|c|c|}
\hline $\begin{array}{l}\text { Number } \\
\text { of crder } \\
\text { of Plate. }\end{array}$ & $n$. & $n^{\prime}$ & D. & $\mathrm{D}^{\prime}$. & $p$ & T. \\
\hline 77 & $\begin{array}{l}134: 5 \\
\ldots \ldots .\end{array}$ & $\begin{array}{l}133 \\
\ldots \ldots .\end{array}$ & $\begin{array}{l}4 \cdot 9+1 \\
4 \cdot 863\end{array}$ & $\begin{array}{l}2585 \\
2526\end{array}$ & $\begin{array}{l}15 \\
15\end{array}$ & $\begin{array}{l}0000001213 \\
0.000001205\end{array}$ \\
\hline 79 & $\begin{array}{l}158 \\
\ldots \ldots . .\end{array}$ & $\begin{array}{l}157 \\
\ldots \ldots\end{array}$ & $\begin{array}{l}5 \cdot 202 \\
5 \cdot 296\end{array}$ & $\begin{array}{l}0.634 \\
0.398\end{array}$ & $\begin{array}{l}29 \\
31\end{array}$ & $\begin{array}{l}0.000001224 \\
0000001229\end{array}$ \\
\hline 80 & $\begin{array}{l}122 \\
\ldots \ldots . .\end{array}$ & $\begin{array}{l}120 \\
\ldots \ldots\end{array}$ & $\begin{array}{l}2580 \\
2521\end{array}$ & $\begin{array}{l}2 \cdot 451 \\
0 \cdot 854\end{array}$ & $\begin{array}{l}33 \\
22\end{array}$ & $\begin{array}{l}0.000001220 \\
0.000001232\end{array}$ \\
\hline 81 & $\begin{array}{l}143 \\
\ldots \ldots .\end{array}$ & $\begin{array}{l}140 \\
\ldots \ldots .\end{array}$ & $\begin{array}{l}2 \cdot 347 \\
2 \cdot 275\end{array}$ & $\begin{array}{l}5 \cdot 378 \\
5.212\end{array}$ & $\begin{array}{l}19 \\
19\end{array}$ & $\begin{array}{l}0.000001194 \\
0.000001205\end{array}$ \\
\hline 82 & $\begin{array}{c}74 \\
\ldots \ldots\end{array}$ & $\begin{array}{r}76 \\
\ldots \ldots\end{array}$ & $\begin{array}{l}1 \cdot 818 \\
1 \cdot 742\end{array}$ & $\begin{array}{l}5 \cdot 498 \\
5 \cdot 438\end{array}$ & $\begin{array}{l}23 \\
23\end{array}$ & $\begin{array}{l}0 \cdot 000001189 \\
0 \cdot 000001197\end{array}$ \\
\hline 83 & $\begin{array}{l}162 \\
\ldots \ldots\end{array}$ & $\begin{array}{l}162 \\
\ldots \ldots\end{array}$ & $\begin{array}{l}2 \cdot 966 \\
2 \cdot 893\end{array}$ & $\begin{array}{l}3 \cdot 050 \\
2 \cdot 843\end{array}$ & $\begin{array}{l}39 \\
37\end{array}$ & $\begin{array}{l}0.000001210 \\
0000001221\end{array}$ \\
\hline 85 & $\begin{array}{l}153 \\
\ldots \ldots\end{array}$ & $\begin{array}{l}153 \\
\ldots \ldots .\end{array}$ & $\begin{array}{l}3 \cdot 147 \\
3080\end{array}$ & $\begin{array}{l}1 \cdot 153 \\
0 \cdot 959\end{array}$ & $\begin{array}{l}28 \\
26\end{array}$ & $\begin{array}{l}0.000001210 \\
0.000001224\end{array}$ \\
\hline
\end{tabular}

Theoretical value 0.000001201. Mean value 0.000001212.

From the tables above given it may be seen that even when the difficulties of measurements are greatest the possible error in evaluating the period will not reach 2 per cent.; whereas for not very short periods a still greater accuracy may be attained. We believe that in the actual state an accuracy superior to that reached by us cannot be obtained, the reason of which will be given below.

Now in order to compare the experimental value with the value of the period as derived from Thomson's theory, it was necessary to obtain the values of the elements entering into Thomson's formula, $i$. e. capacity, resistance, and self-induction of the discharge-circuit, with an accuracy not inferior to that pointed out above. It is thus necessary to explain briefly the method and the precautions used in measuring those elements of the circuit.

\section{Capacity, Resistance, and Self-Induction of Circuit.}

\section{(a) Condenser.}

13. In order to know the capacity with due accuracy, as well for measuring the period as for measuring the disposable energy, which we had to determine when studying 
the distribution of the discharge over the different parts of the circuit, it was first of all necessary that the condenser should not offer such difficulties as wonld arise from the penetration of the charge and from a delay of polarization, which always occur with condensers having solid dielectrics.

This could be obtained only by adopting an air-condenser constructed especially for this investigation.

It was made up of 70 plates of mirror-glass, plane, coated with tinfoil on both sides and separated from one another by small glass prisms.

The mirror-glass plates are rectangular; their surface is $70 \times 35 \mathrm{cms}$., with a thickness variable from one plate to another, and ranging from 7 to $10 \mathrm{~mm}$. On each of them, as has been mentioned, there is extended on both faces a thin sheet of tinfoil of one piece, caused to adhere to the glass by special precautions, so as to prevent folds as well as any airbubbles being formed. The tinfoils, after being extended on the glass, were all cut to the exact dimensions $63 \times 28 \mathrm{cms}$, so as to leave free around them a margin of glass $3.5 \mathrm{cms}$. in breadth. The two tinfoils of each plate were connected to each other by means of a thin brass strip (about $4 \mathrm{~mm}$. in breadth), which at the same time served to establish convenient communications.

These 70 plates were arranged in two piles of 35 each,the first and last plates of either pile having tinfoil on the internal face only. As the interval between two successive plates should remain unaltered and well known, each couple was separated by six small glass prisms, chosen equal among themselves to a hundredth of a millimetre by means of a spherometer.

The prisms of the pile of condensers No. 1 we found to be of a mean thickness of $0.743 \mathrm{~cm}$., those of the pile No. 2 being of a mean thickness of $0.738 \mathrm{~cm}$. In both of these two condensers the even-numbered and the uneven-numbered plates respectively were put in connexion with each other, the respective brass strips being then gathered in two clusters, which were connected to two terminals carried by glass rods.

Each condenser was placed on a solid wooden bench, the respective plates being carried laterally by six glass angles, so as to secure absolute stability. The apparatus was finally protected by a glass jacket, in the interior of which the air was kept dry by means of sulphuric acid.

\section{(b) Measurements of Capacity.}

14. As the dimensions of our condenser are known with accuracy, its capacity could be derived from the well-known formula of Maxwell ('Treatise,' vol. i. \$ 196). 
But we did not limit ourselves to this theoretical value in calculating the results of our investigations, as it results from experiments (not yet published) made for this purpose in our Institute by Dr. Gragnani, that the above formula does not hold for condensers of the dimensions used by us ; and as, moreover, in this condenser each armature is formed by two sheets of tinfoil separated by a plate of glass from 7 to $10 \mathrm{~mm}$. in thickness, the departures from the theoretical conditions this formula holds for are still greater.

In addition, it is impossible to calculate with certainty what influence the neighbourhood either of conductive masses or of the walls and the floor may have on the effective capacity.

Moreover, though the plates as used with our experiments are of mirror-glass and well worked, one cannot warrant their being perfectly plane and accurately parallel among one another.

We therefore measured the capacity of our condenser, either by comparison with a standard condenser or by determining experimentally the absolute value.

\section{Experimental Value.}

15. (1) By comparison with a Standard Condenser.-The standard, kindly lent by Prof. Roiti, hears the number 1099 of the firm Latimer Clark, Muirhead, \& Co. (Westminster), and is made up of plates of tinfoil separated by sheets of mica. The value of the capacity as assigned by the constructing firm is $\frac{1}{3}$ microfar.; that found by Prof. Roiti* by means of special determinations is 0.3359 microfar., very nearly the same as the value 0.3336 found by Glazebrook $\dagger$ for another standard forwarded by the same firm.

It should be borne in mind, however, that in calculating the absolute value of the capacity, Roiti adopted for the B.A. unit of resistance the value 0.9883 legal ohms; whereas in the Chicago Congress of the year 1893 it was establisbed that 1 B.A. should be equal to 0.48703 international ohms; the value as given by Roiti should hence be multiplied by $\frac{0 \cdot 9883}{0.98703}=1 \cdot 0013$, in order to reduce it to the absolute units now adopted.

It thus becomes

$0.3359 \times 1 \cdot 0013=0.3363$ microfarad.

The comparison between this standard and our air-condenser

* Nuovo Cimento [3] xxi. p. 137 (1887).

$\dagger$ Phil. Mag. [5] xviii. p. 98 (1884). 
was made by discharging them successively through a ballisti galvanometer, after bringing their armatures to potentialdifferences whose ratio was known, and which were chosen so as to have deflexions of the galvanometer-needle of the same order of magnitude in both cases.

The charging current was given by three Tudor accumulators, whose circuit was kept permanently closed through a thick argentan spiral, of a total rasistance $51 \cdot 14$ B.A.

Tocharge the standard condenser a deviation of the current between one terminal $\mathrm{A}$ of the spiral and a point $\mathrm{B}$ distant about $2_{20}^{1}$ of the length of the spiral was taken; to charge the air-condenser the deviation was taken at the two terminals of the spiral.

The ballistic galvanometer was of the Du Bois and Rubens type, the duration of a complete oscillation of its needle being 13 seconds. 'The charge of the condenser was kept on 1 second.

From this comparison we obtained for our condenser the value $C=0.016(001$ microf., this value agreeing very well with the value $\mathrm{C}=0.015972$ microf. obtained by substituting for the resistances $\mathrm{AB}$ and $\mathrm{AC}$ of the rheostat above mentioned two other far greater resistances, composed of two Edelmann resistance-boxes of 530 and 9690 units respectively.

The average of those two values gives for the capacity in question

$$
\mathrm{O}=0.015987 \text { microf., }
$$

i. e. 14388 electrostatic C.G.S. units.

16. (2) Absolute Measurements of the Capacity.- 1 n order to have more reliable values for the capacity of our aircondenser we decided to make, as above stated, determinations in absolute measure also by the bridge method, as suggested by J. J. Thomson*.

The arrangement used by us is exactly the same as the one previously adopted and described by Prof. Roiti†.

let $a, b, d, g$, and $p$ denote the resistances of the three branches of the bridge, the galvanometer, and the pile resirectively, and $n$ the number of oscillations per second of the tuning-fork ; the value of the capacity will be given by

$$
\mathbf{C}=\frac{a\left[(a+d+g)(a+b+p)-a^{2}\right]}{n\lfloor(a+b+p)(a+d)-a(a+b)\rfloor[(a+d+g)(a+b)-a(a+d)]} .
$$

As an interrupter we made use of an electromagnetic tuning-fork run by another tuning-fork in unison. These tuning-forks, kindly lent by Prof. Roiti, are constructed in

* Phil. Trans. of tie R. Suc. part iii. p. 707 (1883).

$\dagger$ Nuveo Cimento, [3] xxi. p. 137 (1887).

Phil. Mag. S. 6. Vol. 5. No. 25. Jan. 1903. 
a manner perfectly similar to that described in the above quoted article. The number $n$ of complete oscillations was about 126 per second. The very regular speed of the tuning-forks-the duration of whose oscillations was obtained by comparison with a Graham pendulum regulated by means of a chronometer of the Royal $\mathrm{Navy}$ - facilitated the execution of these measurements, from which we derived the following values :-

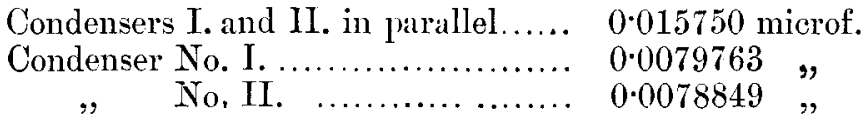

17. Resuming, we may write in the following table the values of the capacities as obtained by the various methods:-

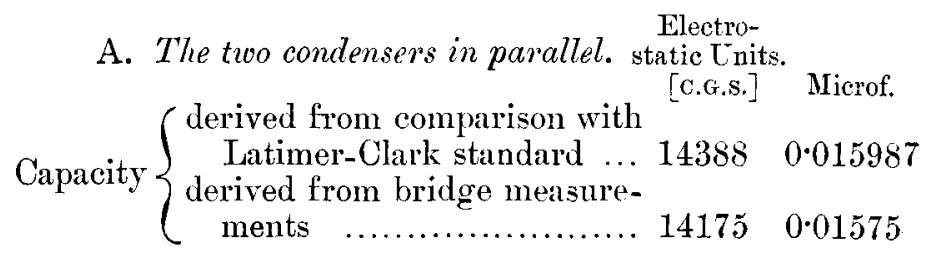

B. Condenser No. 1 only.

Capacity derived from bridge measurements $7178 \quad 0.007976$

C. Condenser No. 2 only.

Capacity derived from bridge measurements

\section{$7096 \quad 0.007885$}

The sum of the capacities of condensers No. 1 and No. 2 thus agrees fairly well with that of these two condensers when connected in parallel, the more so as measurements of the capacity of each condenser apart will present less certainty on account of their small value, and as the neighbourhood of the other condenser will have a slight influence on the capacity of either of them.

The smallness of the difference between the absolute value as found by us by the bridge method and the one derived from a comparison with the Latimer-Clark standard may be considered as an evidence of the accuracy of our measurements. This difference is probably due to the fact that the standard may have undergone a slight variation in the fifteen years passed since Prof. Koiti made his experiments, and that with the comparative experiments the chargo lasted 1 sec., 
whereas with those performed with the bridge it lasted only about $\overline{5}{ }^{1} 0$ of a sec.

With the latter ones a greater approximation to the conditions of action of the condenser during the measurements of the period of oscillation is thus secured.

We will therefore presume that the value most suitable for our calculations is the one derived from our absolute determinations, i.e.

Capacity. [C.G.S.]

Microf.

For condenser No. 1.... 7178

0.007976

No. 2..... 7096

0.007885

For both condensers in

parallel ............... 14175

$0 \cdot 01575$

For both condensers in series

3568

0.003965

18. To these values for the capacity of the condenser there are to be added those of the capacity of the remaining portions of the circuit; but within the limits of accuracy of our determinations in most cases this additional amount may simply be neglected.

The case, in fact, where in our experiments this supplementary capacity had its maximum value, was the one of the discharge-circuit being made up of a wire $1594 \mathrm{~cm}$. in length, $0.08 \mathrm{~cm}$. in diameter, and arranged in the form of a square at $85 \mathrm{~cm}$. from the walls of the room where experiments were made.

The capacity of this wire, as calculated in electrostatic measure by the formula

$$
\mathrm{C}=\frac{7}{2 \log \frac{2 d}{r}}
$$

( $r$ being the radius of the wire, $l$ its length, and $d$ its distance from the walls) was found to be equal to $97 \mathrm{~cm}$. In this case we took this correction into account, whereas in all other cases it was found to be quite negligible as compared with the capacity of the condenser, which for no experimental arrangement was below $3568 \mathrm{~cm}$.

\section{Resistance of Metallic Cireuit and of Spark. a. Principle of Method.}

19. With these first researches the value of the resistance of the circuits used by us was negligible in calculating the period of ascillation by Thomson's formula. But on the other hand, the knowledge of the true value of the resistance C 2 
offered by the metallic parts to the oscillatory discharge was indispensable to us as an element of comparison, in order to derive from it the effective resistance of the spark.

This comparison was made by measuring the amount of heat evolved by the same discharge either in the single metallic portions of the circuit or in the spark, and for this purpose we made use of special calorimeters.

\section{$\beta$. Calorimeters.}

20. Calorimeters for metallic circuit.-Those adopted by us for measuring the energy evolved in the metallic portions of the circuit had the form shown in fig. 5 .

The rectilinear wire or the spiral through which the condenser was discharged terminated in two short platinum wires fused to both ends of a glass tube. To this tube there was connected in a vertical position the uniform capillary tube $\mathrm{C}$, conveniently divided and soldered by its lower part to a wider tube, to which the cock $R$ was connected, the latter being, by means of a rabber tube, put into connexion with the small mercury reservoir $M$. The whole of the tube $T$, the interior of the tube on which the spiral was wound, and part of the capillary tube $\mathrm{C}$ were filled up with toluol.

The mercury reached at least one centimetre above the cock $\mathrm{R}$, allowing thus of the height of toluol in the capillary tube $C$ being regulated, and preventing its leaving by the cock $R$. Round the calorimeter thus formed a glass jacket was placed, in order to regularize the interchange of heat with the atmosphere.

21. Calorimeter for spark.-This was made up of two ovoidal recipients $R^{\prime}$ (fig. 6 ), one of which was interior to the other, the interval being filled up with toluol occupying also the capillary tube ' $\mathrm{T}$.

The latter was, on the other liand, connected to a reservoir P containing mercury by a tube furnished with a cock and a rubber tube. By raising or lowering $P$, the hoight of mercury in the tube, and thus that of the toluol in the tube $\mathrm{T}$ could be varied. 
Round the exterior recipient $R$ there was wound a sufficient layer of wool cloth, the whole being placed within a wooden box $\mathrm{C}$, and being capable of moving by means of the arm NO, to which it was attached, along the brass rod A, and being thus raised to different heights.

We had to make use of the arrangement above described in order to cause the spark to pass frecly when taking the photographs.

When photographs had to be taken, the box was fixed at the level shown in fig. 6 . In order next to. insert the spark into the calorimeter it sufficed to raise the arm NO.

Fig. 6.

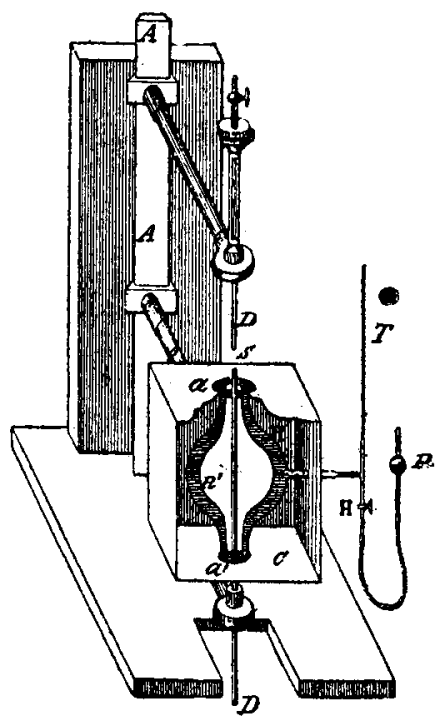

A good closing of the two openings $a a^{\prime}$ of the calorimetric recipient $R$ was obtained by passing the brass rods $D, D^{\prime}$ of the spark-gap through rubber tubes at the part near the interruption where the spark occurred. This method of closing allowed of placing the calorimeter in position with all desirable facility and speed when the heat evolved in the spark was to be determined.

This form of calorimeter seemed more adequate than those previously used by other experimenters, as we avoided the trouble due to the exilosive and electrostatic effects of the spark. Moreover, we aroided the difficulties.met with in the case of air-calorimeters being used, in the accurate determination of the part played by the expansion of the gas in 
the displacement of the liquid column in a capillary tube. If the tube be not of perfectly constant calibre, this displacement is influenced to a notable degree by the capillary action.

\section{$\boldsymbol{\gamma}$. Standardizing of Calorimeters.}

22. In order to obtain in absolute measure from the displacement of the meniscus in the capillary tube of the calorimeters the energy evolved within them we effected their standardizing in the following manner :-

(a) In the case of the metallic spiral calorimeters there was kept on during a given time a continuous current of known intensity, from whose value, together with the value of the resistance offered by the spiral to continuous currents (this resistance being measured by an Elliott bridge), the energy spent in the spiral was calculated, and hence the relation between this energy and the displacement of the toluol column in the calorimeter was ohtained.

(b) In the case of the spark calorimeter we proceeded in the same manner, after, however, connecting the two terminals of the spark-gap with a small constantan spiral of known resistance.

The readings of the calorimeters-made at a distance with a telescope-were effected in both cases by determining from minute to minute the displacements presented by the top of the toluol column five minutes before beginning experiments, during experiments, and five minutes afterwards.

The passage of the continuous current during the standardizing experiments, as well as the passage of discharges during those of definitive measurements, did not last beyond 40 seconds. Readings were always taken by night, in order to have as small variations as possible of temperature in the room, and heat changes with the exterior were taken account of by calculations analogous to those made in pyrheliometric researches.

In the table below the data relative to the five calorimeters we made use of during our researches are recorded.

\section{Spiral Calorimeter.}

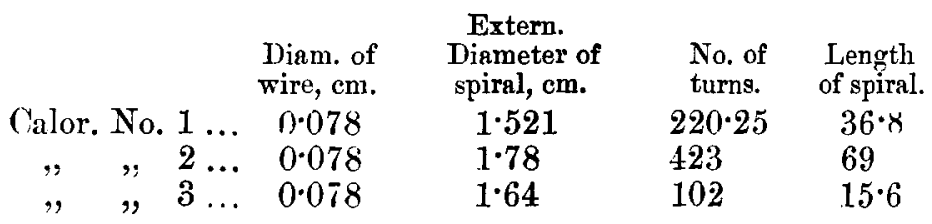


Rectilinear Wire Calorimeter.

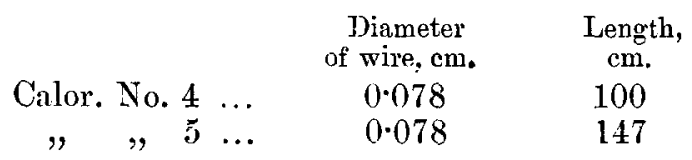

The constant of the spark calorimeter was found equal to $\mathrm{C}_{5}=0.0429$ cal./gr. For the remaining calorimeters we found

$$
\begin{aligned}
& \mathrm{C}_{1}=0.0668 \mathrm{cal} . / \mathrm{gr} . \\
& \mathrm{C}_{2}=0.0876 \quad, \\
& \mathrm{C}_{3}=0.0871 \quad " \\
& \mathrm{C}_{4}=0.0399 \quad,
\end{aligned}
$$


on Nature of Discharge.

23. We have already pointed out the importance that an exact knowledge of the metallic portions of the dischargecircuit had for our researches.

In the case of common copper wires stretched out into a straight line, the resistance $\mathrm{R}^{\prime}$ opposed by a conductor of length $l$ to an oscillating current is given, according to Lord Rayleigh*, by

$$
\mathrm{R}^{\prime}=\mathrm{R}\left(1+\frac{1}{12} \frac{p^{2} l^{2} \mu^{2}}{\mathrm{R}^{2}}-\frac{1}{180} \frac{p^{4} l^{4} \mu^{4}}{\mathrm{R}^{4}}+\ldots\right), \quad .
$$

$\mathrm{R}$ being the resistance of the same wire for continuous currents, $\mu$ its magnetic permeability, and $p=2 \pi n, n$ being the frequency of current.

For the highest values of frequency, Lord Rayleigh's theory shows that this resistance $\mathbf{R}^{\prime}$ has a limiting value as follows :-

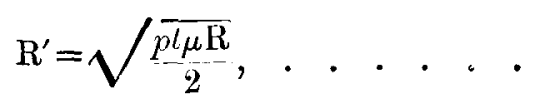

or

$$
\mathrm{R}^{\prime}=\pi a \mathrm{R} \sqrt{\frac{n \mu}{\sigma}}
$$

$\approx$ being the diameter and $\sigma$ the specific resisiance of the conductor.

This formula is equal to the one deduced for very high values of $n$ from the theory of electric oscillations in rectilinear conductors developed by Stefan $\dagger$.

* Phil. Mag. [5] xxi. p. 781 (1886).

$\dagger$ Wied. Ann. xli. p. $400(1890)$. 
The results are recorded in the following table, where they are arranged for increasing values of frequency and of the number of turns of wire in unit of length of the spiral.



From these results it may be seen that for every spiral the resistance will always increase with increase of frequency and also with diminution of distance of the spires.

This phenomenon leads us to suppose that, while in a rectilinear conductor the current will pass through a thin superficial layer only, it becomes localized in a still more reduced space when the same conductor is wound into a spiral; and this may be expected, considering the mutual induction effects between the various portions of the circuit.

This localization is likely to affect the value of the selfinduction coefficient of the circuit, but it may be easily understood - a fact borne out by the experiments we undertook for this purpose-that this influence is quite insignificant in comparison with the effect upon the resistance.

26. From all the facts above mentioned it thus results that the true value of the resistance of our spirals for a given period will be obtained by multiplying the value for the resistance $\mathbf{R}_{\tau}$, exbibited by the same wire when drawn out to a straight line, for the same period, by the ratio $\frac{\rho}{\rho^{\prime}}$, as found experi-
mentally in the above manner.

We thus have for our experiments the following values for $\mathrm{R}_{\tau}{ }^{\prime}$ :-

For the calorimeter No. 2 :

$$
\mathrm{R}_{\tau^{\prime}=6 \cdot 7 \cdot 10^{-6}=0.983 \times 1 \cdot 79=1 \cdot 76 .}
$$


For the calorimeter No. 1 :

$$
\begin{aligned}
& \mathrm{R}_{\tau^{\prime}=4.3 \times 1 \theta^{-6}=0.539 \times 1.96=1.06 ;} \\
& \mathrm{l}_{\tau^{\prime}=3 \times 10^{-6}=0.613 \times 2.15=1.38} \text {; } \\
& \mathrm{R}_{\tau^{\prime}=2 \cdot 2 \times 10^{-6}=0.761 \times 2 \cdot 17=1.65} \text {. }
\end{aligned}
$$

For the calorimeter No. 3 :

$$
R_{\tau^{\prime}=1 \cdot 7 \times 10^{-6}=0.440 \times 1 \cdot 84=0.827 .}
$$

\section{F. Self-Induction.}

27. In the case of the self-induction also the theoretical treatment with regard to alternating currents has been worked out only for some special forms of plain circuits, and calculations relating to circuits wound into a spiral are completely wanting, as in this case neither Maxwell's method of the mean geometrical distance * nor Lord Rayleigh's $\dagger$ method, nor those derived from the theory of oscillatory discharges mar be made use of, as pointed out by Stefan $\ddagger$.

$\dot{A}$ s, however, we wanted to ascertain this element also with sufficient accuracy, we used the following eircuits in our experiments relative to the period measurements, the theoretical value of the self-induction being known in those cases.

(a) Square of copper wire: radius of section of wire $0.04 \mathrm{~cm}$. ; length of side $l=398.6 \mathrm{cms}$.

(b) Circle of copper wire:-

Circle No. 1 : radius of section of wire $0.226 \mathrm{~cm}$. ; diameter of circle $201 \mathrm{cms}$.

Circle No. 2 : radius of section of wire $0.226 \mathrm{~cm}$.; diameter of circle $57 \cdot 2 \mathrm{cms}$.

The wires these circuits are made up of are stretched out on suitable wooden frames, and the necessary insulation is obtained by small ebonite cylinders.

In order to keep the sides of the square as far as possible from conductive masses during the experiments, the wooden frame was inclined at 50 degrees to the horizon, and had one side at the level of the spark-gap. The mean distance between the sides of the square, the walls of the room, and the ceiling was $0.85 \mathrm{~m}$.

Now, according to Lord Rayleigh $\S$, the effective selfinduction $\mathrm{I}^{\prime}$ of a plane conductor, $l$ in length and of an ohmic

* Cfr. Wien, Wied. Ann. liii. p. 928 (1894).

† Phil. Mag. xxi. p. 381 (1886).

Wied. Ann. xli. pp. $400 \& 421$ (1890).

$\$$ Phil: Mag. [5] xxi. p. 381 (1886). 
the discharges were capable of producing greater effects in the former calorimeter than in the latter.

We performed some new experiments, however, using continuous currents, sent through the calorimeters at long intervals.

The arrangement adopted for this purpose consisted in closing the accumulator circuit by means of a pendulum which carried a point entering a mercury beaker placed below, in the position corresponding to the position of rest. This pendulum was $2.50 \mathrm{~m}$. in length and accomplished an oscillation of $1.80 \mathrm{~m}$. in $1.6 \mathrm{sec}$.

The length of the mercury beaker was $1 \mathrm{~cm}$, so that the duration of the passage of the current was about $\frac{1}{25}$ of the interval separating two successive passages.

With these currents so markedly intermittent we obtained also between the amounts of heat evolved in the two portions of circuit, the same ratio as obtained in the case of a contimuous passage of current.

We may therefore conclude that the indications of our calorimeters are really due to the heat evolved in the metallic wire.

As we do not think it necessary to give here tho tables containing the results of the measurements made to ascertain the value of the ratio $\frac{\rho}{\rho^{\prime}}$, we record the final values derived from them, i.e., the means of three series agreeing well with one another (p. 27).

From an inspection of the table opposite it results that the effective resistance of a spiral (ratio between the calorific energy absorbed by the latter and the mean square of the intensity of current) is greater than the effective resistance offered by the same wire when drawn out into a straight line.

25. In order to test the possible influence of the neighbourhood of the spiral on this increase of resistance, we made some experiments with four other spirals, $a, l, c, d$, and, by the method above mentioned, determined the ratio $\frac{\rho}{\rho^{\prime}}$. The copper wires the spirals $a, b, c$ were constructed with had equal length and thickness, whereas the spiral $d$ contained a greater length of wire.

Simultaneously we investigated the possible influence of the frequency of current, owing to the more or less considerable capacities it inserts into the discharge circuit. 
Mean of Deviations Observed.

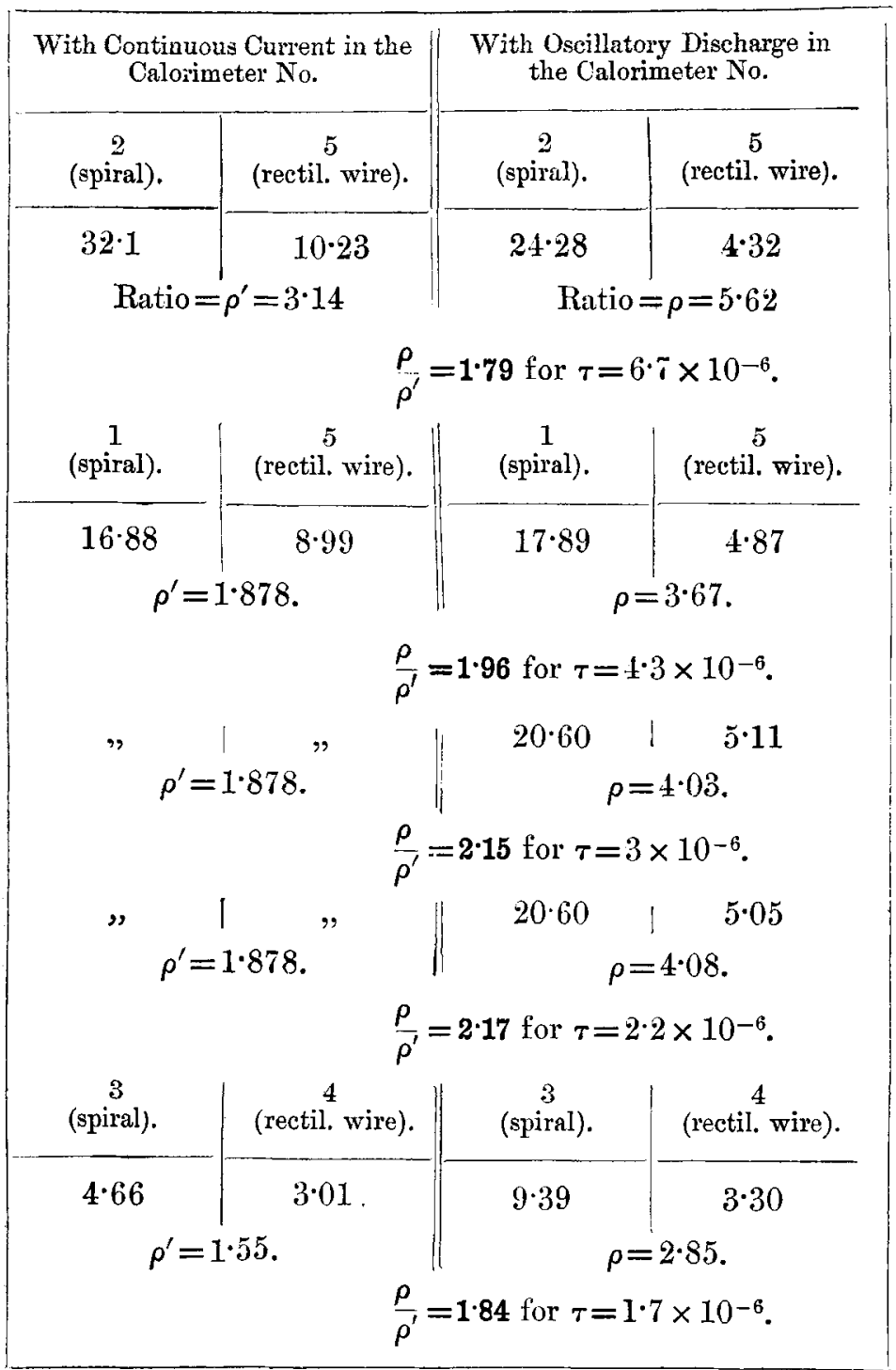

N.B. Calorimeters are placed in series. 
The results are recorded in the following table, where they are arranged for increasing values of frequency and of the number of turns of wire in unit of length of the spiral.

\begin{tabular}{|c|c|c|c|c|c|c|}
\hline \multirow[b]{2}{*}{ Spiral. } & \multirow[b]{2}{*}{$\begin{array}{c}\text { No. of } \\
\text { turns per } \\
\text { em. }\end{array}$} & \multicolumn{5}{|c|}{ Values of $\frac{\rho}{\rho^{i}}$. } \\
\hline & & $\begin{array}{l}\text { Con- } \\
\text { tinuous } \\
\text { current. }\end{array}$ & $\begin{array}{c}30 \text { large } \\
\text { glass } \\
\text { leyden-jars } \\
\text { and air- } \\
\text { condensers } \\
\text { in parallel. }\end{array}$ & $\begin{array}{l}\text { Air-con- } \\
\text { dengers in } \\
\text { parallel. }\end{array}$ & $\begin{array}{l}2 \text { air-con- } \\
\text { densers in } \\
\text { series. }\end{array}$ & $\begin{array}{l}\text { One small } \\
\text { condenser. }\end{array}$ \\
\hline $\begin{array}{cc}\text { Spiral } & a \\
, & b \\
" & c \\
, & d\end{array}$ & $\begin{array}{l}2 \cdot 42 \\
3 \cdot 82 \\
622 \\
7 \cdot 52\end{array}$ & $\begin{array}{l}1 \\
1 \\
1 \\
1\end{array}$ & $\begin{array}{l}1.02 \\
1.17 \\
1.48 \\
1.56\end{array}$ & $\begin{array}{l}1 \cdot 14 \\
1 \cdot 31 \\
1 \cdot 66 \\
1 \cdot 72\end{array}$ & $\begin{array}{l}1 \cdot 18 \\
1 \cdot 34 \\
1 \cdot 68 \\
2 \cdot 03\end{array}$ & $\begin{array}{l}1 \cdot 30 \\
1 \cdot 70 \\
1 \cdot 89 \\
2 \cdot 37\end{array}$ \\
\hline
\end{tabular}

From these results it may be seen that for every spiral the resistance will always increase with increase of frequency and also with diminution of distance of the spires.

This phenomenon leads us to suppose that, while in a rectilinear conductor the current will pass through a thin superficial layer only, it becomes localized in as still more reduced space when the same conductor is wound into a spiral; and this may be expected, considering the mutual induction effects between the various portions of the circuit.

This localization is likely to affect the value of the selfinduction coefficient of the circuit, but it may be easily understood-a fact borne out by the experiments we undertook for this purpose- - that this influence is quite insignificant in comparison with the effect upon the resistance.

26. From all the facts above mentioned it thus results that the true value of the resistance of our spirals for a given period will be obtained by multiplying the value for the resistance $\mathbf{R}_{\tau}$, exhibited by the same wire when drawn out to a straight line, for the same period, by the ratio $\frac{\rho_{\bar{\rho}}}{\rho^{\prime}}$, as found experimentally in the above manner.

We thus have for our experiments the following values for $\mathrm{R}_{\tau}^{\prime}:$ -

For the calorimeter No. 2:

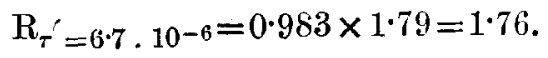


For the calorimeter No. 1 :

$$
\begin{aligned}
& R_{\tau^{\prime}=4 \cdot 3 \times 1 \theta^{-6}}=0.539 \times 1 \cdot 96=1 \cdot 06 ; \\
& R_{\tau^{\prime}=3 \times 10^{-6}=0.643 \times 2 \cdot 15}=1 \cdot 38 ; \\
& R_{\tau^{\prime}=2 \cdot 2 \times 10^{-6}}=0.761 \times 2 \cdot 17=1 \cdot 65 .
\end{aligned}
$$

For the calorimeter No. 3 :

$$
\mathrm{R}_{\tau^{\prime}=1 \cdot 7 \times 10^{-6}=0.440 \times 1.84=0.827} .
$$

\section{F. Self-Induction.}

27. In the case of the self-induction also the theoretical treatment with regard to alternating currents has been worked out only for some special forms of plain circuits, and calculations relating to circuits wound into a spiral are completely wanting, as in this case neither Maxwell's method of the mean geometrical distance* nor Lord Rayleigh's $\dagger$ method, nor those derived from the theory of oscillatory discharges may be made use of, as pointed out by Stefan $\ddagger$.

As, however, we wanted to ascertain this element also with sufficient accuracy, we used the following circuits in our experiments relative to the period measurements, the theoretical value of the self-induction being known in those cases.

(a) Square of copper wire: radius of section of wire $0 \cdot 04 \mathrm{~cm}$.; length of side $l=398 \cdot 6 \mathrm{cms}$.

(b) Circle of copper wire:-

Circle No. 1: radius of section of wire $0.226 \mathrm{~cm}$.; diameter of circle $201 \mathrm{cms}$.

Circle No. 2 : radius of section of wire $0.226 \mathrm{~cm}$; diameter of circle $57 \cdot 2 \mathrm{cms}$.

The wires these circuits are made up of are stretched out on suitable wooden frames, and the necessary insulation is obtained by small ebonite cylinders.

In order to keep the sides of the square as far as possible from conductive masses during the experiments, the wooden frame was inclined at 50 degrees to the borizon, and had one side at the level of the spark-gap. The mean distance between the sides of the square, the walls of the room, and the ceiling was $0.85 \mathrm{~m}$.

Now, according to Lord Rayleigh $\S$, the effective selfinduction $L^{\prime}$ of a plane conductor, $l$ in length and of an ohmic

* Cfr. Wien, Wied. Ann. liji. p. 928 (1894).

† Ṕhil. Mag. xxi. p. 381 (1886).

+ Wied. Ann. xli. pp. $400 \& 421$ (1890).

$\S$ Phil. Mag. [5] xxi. p. 381 (1886). 
resistance equal to $R$, for currents of high frequency will be given by

$$
\mathrm{L}^{\prime}=l\left(\mathrm{~A}+\sqrt{\frac{\mathrm{R}}{2 p l}}\right)
$$

$p$ being $=2 \pi n$ and $\mathrm{A}$ being a constant. This constant, as results immediately from formula (20) of the quoted paper, by putting $p=0$, is connected to the self-induction for continuous currents by the relation

$$
\mathrm{L}_{0}=l\left(\mathrm{~A}+\frac{1}{2}\right) .
$$

Hence the preceding formula may be given the form

$$
\mathrm{L}^{\prime}=\mathrm{L}_{0}-\frac{1}{2}\left(1-\sqrt{\frac{\mathrm{R}}{\pi n l}}\right) . . . .
$$

For the various circuits above mentioned the value for $L_{0}$ is given for a square ${ }^{*}$ of the perimeter $l$ by

$$
\mathrm{L}_{0}=2 l\left(\log _{e} \frac{l}{r}-1.9103\right),
$$

for a circle of the radius $a$ by

$$
\mathrm{L}_{0}=4 \pi a\left(\log _{e} \frac{8 a}{r}-1 \cdot 75\right),
$$

$r$ being the radius of the wire $\dagger$.

Wien $\ddagger$ controlled the values for $L_{0}$, calculated by these formulæ and agreeing with each other to 0.1 per cent., by those obtained from accurate measurements; they thus deserve full credit. By substituting them in the formula (1) we may calculate the self-induction the above circuits exhibit for each period of the discharges we have photographed the spark of.

The following values were thus obtained :-

For the square of copper wire:

$$
\begin{array}{ll}
\mathrm{T}=0.00000425, & 0.00000303, \\
\mathrm{~L}=27390 \mathrm{cms} ., & 27329 \mathrm{cms} .
\end{array}
$$

For the circle No. 1 :

$$
\begin{array}{lll}
\mathrm{T}=0.00000235, & 0.00000167, & 0.00000120, \\
\mathrm{~L}=7829 \mathrm{cms} ., & 7824 \mathrm{cms} ., & 7810 \mathrm{cms} .
\end{array}
$$

* This formula may be deduced by simple algebraical operations from the one given in Mascart, Electr. et Magn. vol. i. p. 630, of the second edition.

$\dagger$ Mascart, l. c. p. 633.

$\ddagger$ Wied. Ann. liii. p. 928 (1894). 
For the circle No. 2 :

$$
\begin{aligned}
& \mathrm{T}=0.0000007, \\
& \mathrm{~L}=1768 .
\end{aligned}
$$

In addition to these plane circuits we also made use of the two following spirals in our period measurements.

Spiral A.-This spiral is wound on an ebonite tube accurately worked and traversed throughout its length by a glass rod preventing any deformations of the former. The wire is placed in a helix cut on the tube by means of the lathe. The diameter of the copper wire it is made up of is $0.08 \mathrm{~cm}$., the mean radius of the cross-section of the spires being $0 \cdot 713 \mathrm{~cm}$. The number of spires per centimetre is $6 \cdot 3025$. The whole of the spiral contains 485 spires. Its self-induction, as measured by Nernst's method with currents of high frequency (see p. 32 ), is $57,230 \mathrm{cms}$.

Spiral B.-The support of this spiral is a large marble cylinder, worked on the lathe with extreme care in the mechanical workshop of our Institute. Its surface may be considered as that of a practically perfect eylinder. The variations of diameter of its cross-section, in fact (this being $23.821 \mathrm{cms}$. at $23^{\circ}$ C.), never reached $0.1 \mathrm{~mm}$.

The length of this cylinder is $98 \mathrm{cms}$. The spiral occupies $85 \mathrm{cms}$., the number of spires being 283 . The mean thickness of the wire it is made up of is $1.435 \mathrm{~mm}$. The spiral itself has been directly wound upon the marble by means of the lathe. In order to prevent any displacement of the spires the whole has been coated with a thick varnish layer of gum-lac. The self-induction of this spiral is $4 \cdot 546000 \mathrm{cms}$.

28 . To these values there have to be added the values relative to the portions of the circuit establishing the communications between the condenser and the spark-gap. In order to diminish the resistance and to have for those portions an easily calculated self-induction, we established the connexions by means of big brass tubes, their external radius being $\rho_{1}=1 \mathrm{~cm}$., the internal radius $\rho_{2}=0.88 \mathrm{~cm}$., and of copper strips $5 \mathrm{cms}$. in width and $\frac{2}{10} \mathrm{~mm}$. in thickness. For these tubes the self-induction is given by $*$

$$
\mathrm{L}=2 l\left\{\log _{e} \frac{2 l}{\rho_{1}}+\frac{\rho_{2}{ }^{2}}{\left(\rho_{1}{ }^{2}-\rho_{2}{ }^{2}\right)^{2}} \log _{e} \frac{\rho_{1}}{\rho_{2}}-\frac{1}{4} \frac{\ddot{\partial} \rho_{2}{ }^{2}-\rho_{1}{ }^{2}}{\rho_{1}{ }^{2}-\rho_{2}{ }^{2}}-1\right\},
$$

and for the strips by

$$
\mathrm{L}=2 l\left\{\log _{e} \frac{2 l}{b}-\frac{\pi}{3} \frac{a}{b}+\frac{1}{2}\right\}
$$

$l$ being the length, $a$ the thickness, and $b$ the width.

* Wien, Wied. Am. liii. p. 928 (1894). 
Hence for the three tubes used by us, being $90 \mathrm{cms}, 80 \mathrm{cms}$., and $71 \mathrm{cms}$. in length respectively, we have the values

$$
\begin{aligned}
& \mathrm{L}_{1}=762 \mathrm{cms} . \\
& \mathrm{L}_{2}=658, \\
& \mathrm{~L}_{3}=567,
\end{aligned}
$$

and for the strip, $20 \mathrm{cms}$. in length,

$$
\mathrm{L}_{4}=103 \mathrm{cms} \text {. }
$$

29. With those experiments which served us to determine the resistance of the spark and whose results we availed ourselves of in order to compare the energy disposable in the discharge with the energy exhibited by the various portions of the circuit, we made use of circnits wound in spirals, as has already been stated; and with those experiments also we photographed the spark.

In order to compare the values for the period of oscillation as obtained experimentally for those sparks with the corresponding theoretical values, it would be necessary to know the self-induction of the spirals, whose dimensions are recorded on page 22 .

As theoretical formulxe to calculate accurately these selfinductions are wanting, we had to compare them with that of circuits capable of being theoretically calculated.

For these comparisons we availed ourselves of the Nernst* differential exciter slightly modified, as to obtain the equilibrium we maintained constant the two comparison capacities and varied one of the two self-inductions. 'The variable selfinduction was made up of a copper wire spiral, of which any number of spires could be employed in our experiments (mean radius of spiral $0.713 \mathrm{~cm}$, thickness of wire $0.8 \mathrm{~mm}$., number of spires to the unit of length 6.3025 ).

The arrangement adopted is shown diagrammatically by

Fig. 7.

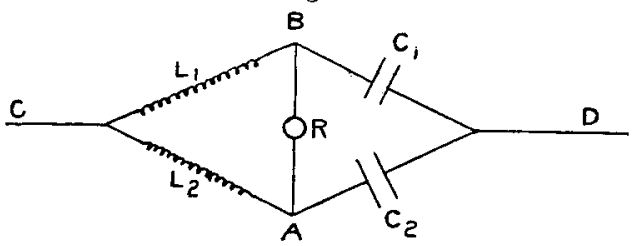

fig. 7, where $L_{1}$ denotes the spiral, $L_{2}$ is the comparison circuit, $\mathrm{C}_{1}$ and $\mathrm{C}_{2}$ are the two comparison condensers, and $\mathrm{R}$ is the detector.

* Wied. Ann. lx. p. 600 (1897). 
After connecting the points $\mathrm{C}$ and $\mathrm{D}$ with the electrodes of a spark-gap and with the poles of a Ruhmkorff coil, there could be sent through the differential exciter currents with a frequency of the same order of magnitude as those of the sparks we have photographed.

Then it was tested whether the contact points $A$ and $B$ between each self-induction and the corresponding condenser were at the same potential. For this purpose we found most convenient the detector suggested by Nernst, made up of a vacuum-tube without electrodes, on whose terminals two strips of tinfoil connected with A and B respectively had been wound.

As is known, the luminosity of the tube will be minimum when the condition

is satisfied.

$$
\mathrm{L}_{1} \mathrm{C}_{1}=\mathrm{L}_{2} \mathrm{C}_{2}
$$

The accuracy of this method depends upon the precision with which this minimum is determined, as any one of the four quantities $\mathrm{L}_{1}, \mathrm{~L}_{2}, \mathrm{C}_{1}, \mathrm{C}_{2}$ undergoes a suall variation. This precision is greatest when the degree of exhaustion in the tube is the one corresponding to the first appearance of cathode rays.

Various numbers of spires of the spiral were successively used until the detector showed a minimum of luminosity. The self-induction $\mathrm{I}_{2}$ of the spiral could be considered as proportional to the number $n_{0}$ of spires used : denoting by $k$ the coefficient of proportionality, the above-mentioned condition of minimum was represented by

$$
\mathrm{L}_{1} \mathrm{C}_{1}=k n_{0} \mathrm{C}_{2} \text {. }
$$

The wire with known self-induction was next replaced by the spiral whose self-induction $x$ had to be determined, and the number of spires was again varied, until for some number $n$ the minimum with the detector was arrived at.

The minimum condition became

$$
x \mathrm{C}_{1}=k n \mathrm{C}_{2} \text {. }
$$

Those two determinations gave the self-induction to be found

$$
x=\frac{n}{n_{0}} \mathrm{~L}_{1}
$$

for high-frequency currents. Our experimental conditions allowed of such a precision in determining the minimum that the numbers $n$ and $n_{0}$, ranging as a rule between 70 and 350 , were ascertained to less than a unit.

Phil. Mag. S. 6. Vol. 5. No. 25. Jan. 1903. 
We succeeded in reaching this degree of accuracy by using the following precautions:-

1. Using two comparison condensers whose capacities $\mathrm{C}_{1}$ and $\mathrm{C}_{2}$ differ as little as possible from each other.

2. Covering all the portions of apparatus employed to produce high-frequency currents (Ruhmkorff-coil, sparkgap, \&c.) with a metallic cage, in order to avoid electrostatic actions between those latter and the various branches of the Nernst bridge.

3. Covering with a metallic cage also the two comparison condensers.

4. Avoiding the use of any conductors in the neighbourhood of the wires, and especially of the spirals.

By this method the following values for the self-induction of our circuits have been obtained :-

$\begin{array}{cc}\text { Circuit. } & \text { Self-induction. } \\ \text { Spiral No. } 1 & 29470 \\ \text { " No. } 2 & 74140 \\ \text { No. } 3 & 17460 \\ \text { Wire No. } 4 & 3669\end{array}$

In these values the self-induction of tubes and copper strips establishing the connexions are also included.

II. On the Magnetic Effect of Electrical Convection.-II. By Harold Pender, Ph.D.*

QINCE the publication of the results of his first experi$N$ ments on the magnetic effect of a moving charged body $t$, the author has continued his investigations, with results in every way confirmatory of those of the previous experiments. A brief account of these later experiments may not be without interest, as they were performed under entirely new and more favourable conditions, and gave results which are far more consistent than those previously obtained.

M. Crémieu $\ddagger$, in criticizing the previous paper of the author, suggested that the agreement between the observed and calculated values of the magnetic effect of the moving charged disks was due to the fact that the speeds and potential of the disks were of such critical values that a slight leak in the insulation would produce the observed effect. The first step then was to test this criticism by varying the speeds and

* Communicated by Prof. J. S. Ames.

+ Phil. Mag. ii. p. 169 (1901); Phys. Rev.xiii. p. 203 (1901).

$\ddagger$ Journ. de Phys., Dec. 1901. 